\title{
Irrigação com águas salinas e aplicação de prolina foliar em cultivo de pimentão 'All Big'
} \author{
Hans Raj Gheyi², Reginaldo Gomes Nobre', Rennan Fernandes Pereira ${ }^{3}$ \\ 'Universidade Federal de Campina Grande, Campina Grande, Brasil \\ ${ }^{2}$ Universidade Federal do Recôncavo da Bahia, Cruz das Almas, Brasil \\ 3Universidade Federal da Paraíba, Areia, Brasil \\ *Autor correspondente, e-mail: geovanisoareslima@gmail.com
}

Geovani Soares de Lima*1, João Batista dos Santos', Lauriane Almeida dos Anjos Soares',

\begin{abstract}
Resumo
Objetivou-se, no presente estudo, avaliar o crescimento e a produção do pimentão 'All Big', em função da irrigação com águas salinas e aplicação foliar de prolina, em pesquisa conduzida em vasos adaptados como lisímetros de drenagem em condições de casa de vegetação, no Neossolo Regolítico Eutrófico de textura franco-arenosa, no município de Campina Grande, PB, Brasil. Utilizouse o delineamento de blocos ao acaso testando-se dois níveis de condutividade elétrica da água de irrigação - CEa (0,6 e 3,0 dS $\left.\mathrm{m}^{-1}\right)$ associado a quatro doses de prolina (0; 10; 20 e $\left.30 \mathrm{mmol}^{-1}\right)$. A irrigação com água de $\mathrm{CEa}=3,0 \mathrm{dS} \mathrm{m}^{-1}$ afetou negativamente o crescimento do pimentão 'All Big', sendo a fitomassa seca de caule a variável mais sensível; os maiores valores para massa fresca, número e peso médio de frutos de pimentão foram obtidos quando se utilizou água com CEa=0,6 dS $\mathrm{m}^{-1}$ e doses de prolina de 12,17 e $0 \mathrm{mmol}^{-1}$, respectivamente; as doses crescentes de prolina não mitigaram o efeito deletério provocado pela salinidade da água de irrigação de $3,0 \mathrm{dS} \mathrm{m}^{-1}$ sobre o crescimento e a produção do pimentão 'All Big'.
\end{abstract}

Palavras-chave: Capsicum annuum L., estresse salino, aminoácido

Irrigation with saline water and foliar application of proline in 'All Big'sweet pepper

\begin{abstract}
It is proposed in this study the evaluation of the growth and yield of 'All Big' sweet pepper under foliar application of proline and irrigation with saline water. The research was conducted in pots adapted as drainage lisimeters under greenhouse conditions, using an Eutrophic Entisol with sandyloam texture in the municipality of Campina Grande, PB, Brazil. A randomized block design was used testing two levels of electrical conductivity of irrigation water - ECW (0.6 and $\left.3.0 \mathrm{dS} \mathrm{m}^{-1}\right)$ associated to four proline levels $\left(0,10,20\right.$ and $\left.30 \mathrm{mmol}^{-1}\right)$. Irrigation with water with $\mathrm{ECW}=3.0 \mathrm{dS} \mathrm{m}^{-1}$ negatively affected the 'All Big'pepper growth and the stem dry mass, being the most sensitive variable; the highest values for fresh mass, number and average weight of pepper fruits were obtained when

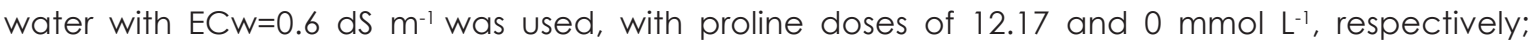
increasing proline doses did not mitigate the deleterious effects caused by irrigation water salinity of $3.0 \mathrm{dS} \mathrm{m}^{-1}$ on growth and yield of 'All Big ' sweet pepper.
\end{abstract}

Key words: Capsicum annuum L., salt stress, aminoacid 


\section{Introdução}

Pertencente à família das solanáceas, o pimentão (Capsicum annuum L.) é cultivado em todo território nacional, sendo uma das dez hortaliças de maior importância econômica no mercado hortifrutigranjeiro, tanto em valor quanto em volume comercializado, podendo ser consumido na forma de frutos verdes, maduros e industrializado em forma de pó (Echer et al., 2002; Silva et al., 2014).

A região semiárida do Nordeste brasileiro é caracterizada por apresentar escassez hídrica e irregularidade de distribuição das chuvas e, desta forma o sistema de produção necessariamente depende da irrigação (Cavalcante et al., 2011). Além disso, nas águas provenientes dos mananciais desta região, os valores de condutividade elétrica superior a 1,5 dS $\mathrm{m}^{-1}$ são comunentes encontradas, o que pode provocar modificações morfológicas, estruturais e metabólicas nas plantas, comprometendo o crescimento, a floração, a qualidade do fruto, a redução do ciclo das culturas e produtividade (Silva et al., 2009; Neves et al., 2010).

Entretanto, os efeitos decorrentes do estresse salino sobre as culturas vêm sendo superados em diversas regiões do mundo, em razão da utilização de espécies tolerantes à salinidade e da adoção de práticas adequadas de manejo da irrigação (Sousa et al., 2012). Neste sentido, diversas pesquisas tem demonstrado uma correlação positiva entre a acumulação de solutos orgânicos ou osmólitos (prolina, glicina betaína, trealose, sacarose entre outros) e a tolerância das culturas ao estresse salino(Ashraf \& Foolad, 2007; Trovato et al., 2008; Verbruggen \& Hermans, 2008; Ashraf et al., 2011).

O aminoácido prolina é o soluto compativel no citossol que contribui para o equilíbrio osmótico intracelular, quando a concentração de íons orgânicos é alta no vacúolo, podendo também proteger enzimas citossólicas quando a concentração de íons aumenta e, consequentemente, manter o potencial hídrico e a turgescência das células (Greenway \& Munns, 1980). Além de osmorregulador, a prolina atua favorecendo - equilíbrio redox em células estressadas (Verbruggen \& Hermans, 2008).
Diante do exposto, objetivou-se com este trabalho avaliar o crescimento e a produção de pimentão 'All Big', em função da irrigação com águas salinas e aplicação foliar de prolina.

\section{Material e Métodos}

O experimento foi conduzido entre os meses de maio e agosto de 2015, em casa de vegetação do Centro de Tecnologia e Recursos Naturais da Universidade Federal de Campina Grande (CTRN/UFCG), no município de Campina Grande, Paraíba, na mesorregião do Agreste Paraibano, situado pelas coordenadas geográficas 7015'18' latitude $S, 35^{\circ} 52^{\prime 2} 28^{\prime \prime}$ de longitude $W$ e altitude média de 550 m; sendo - clima da região, conforme a classificação climática de Koppen, adaptada ao Brasil, do tipo Csa, que representa clima mesotérmico, subúmido, com período de estiagem quente e seco (4 a 5 meses) e período chuvoso de outono a inverno. Os dados climatológicos referentes ao período de condução do experimento estão apresentados na Figura 1.

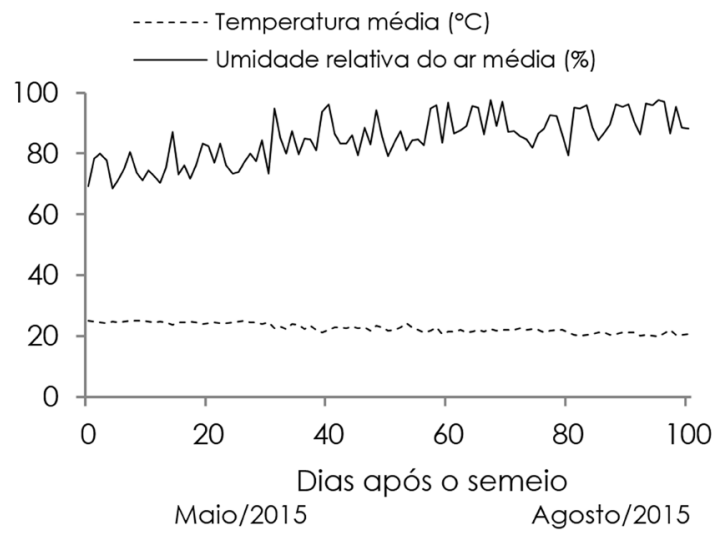

Figura 1. Valores médios de temperatura $\left({ }^{\circ} \mathrm{C}\right)$ e umidade relativa do ar (\%), coletados durante a condução da pesquisa.

A casa de vegetação utilizada para a condução desta pesquisa é do tipo capela com a cobertura de telha transparente e translúcida, possuindo laterais com meia parede, na altura de $0,80 \mathrm{~m}$, de alvenaria e 3,2 m coberta com tela branca, construída em estrutura de alvenaria e ferro, com orientação no sentido leste oeste, possuindo $9 \mathrm{~m}$ de comprimento, $8 \mathrm{~m}$ de largura e $4 \mathrm{~m}$ de altura do pé direito.

Os tratamentos foram distribuídos em delineamento de blocos inteiramente casualizados em esquema fatorial $2 \times 4$, com 
quatro repetições, correspondendo a dois níveis de condutividade elétrica da água de irrigação - CEa $\left(0,6\right.$ e 3,0 dS $\left.\mathrm{m}^{-1}\right)$ associado a quatro níveis de aplicação foliar semanal de prolina $10 ; 10 ; 20$

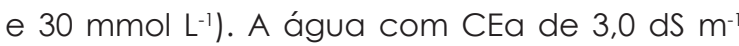
foi preparada utilizando-se os sais de cloreto de sódio ( $\mathrm{NaCl})$, cálcio $\left(\mathrm{CaCl}_{2} \cdot 2 \mathrm{H}_{2} \mathrm{O}\right)$ e magnésio $\left(\mathrm{MgCl}_{2} \cdot 6 \mathrm{H}_{2} \mathrm{O}\right)$ de modo a se ter uma proporção equivalente de 7:2:1, entre $\mathrm{Na:Ca:Mg}$, sendo a quantidade determinada levando em consideração a relação entre a CEa e a concentração de sais $\left(10^{*} \mathrm{mmol}_{\mathrm{c}} \mathrm{L}^{-1}=1 \mathrm{dS} \mathrm{m}^{-1}\right)$.

O hibrido de pimentão utilizado no experimento foi o 'All Big', pertencente ao grupo conhecido como cascadura; este material possui crescimento ereto, de porte baixo, a polpa firme e grossa e de sabor doce, alta produtividade e ciclo em torno de 120 dias (Araújo et al., 2009). Além disso, o hibrido é tolerante a podridão do colo (Phytophthora capsici) e mosaico-comum (TOMV).

As mudas de pimentão, híbrido 'All Big', foram produzidas em bandejas de poliestireno expandido com 128 células, utilizando o substrato comercial Plantmax ${ }^{\oplus ;}$ as irrigações ocorreram duas vezes ao dia, de manhã e à tarde e, quando as plântulas emitiram o segundo par de folhas definitivas foi realizado o transplantio para os vasos, conforme metodologia recomendada por Resende et al. (2010) para a formação de mudas de alface.

Para condução das plantas, utilizaramse vasos plásticos de $10 \mathrm{~L}$ de capacidade, com $26 \mathrm{~cm}$ de diâmetro superior, $16,5 \mathrm{~cm}$ de diametro inferior e $24 \mathrm{~cm}$ de altura, preenchidos com uma camada de $0,3 \mathrm{~kg}$ de brita (número zero) a qual cobria a base e de $14 \mathrm{~kg}$ de um Neossolo Regolítico Eutrófico, textura francoarenosa (profundidade $0-20 \mathrm{~cm}$ ), devidamente destorroado e proveniente da zona rural do município de Esperança, PB, cujas características físico-hídricas e químicas (Tabela 1) foram determinadas no Laboratório de Irrigação e Salinidade da UFCG, conforme metodologias propostas por Claessen (1997).

Tabela 1. Características químicas e físico-hídricas do solo utilizado no experimento

\begin{tabular}{|c|c|c|c|c|c|c|c|c|c|}
\hline \multicolumn{10}{|c|}{ Características químicas } \\
\hline \multirow{2}{*}{$\begin{array}{c}\mathrm{pH}\left(\mathrm{H}_{2} \mathrm{O}\right) \\
1: 2,5\end{array}$} & \multirow{2}{*}{$\begin{array}{c}\text { M.O } \\
\text { dag kg-1 }\end{array}$} & \multirow{2}{*}{$\begin{array}{c}\mathrm{P} \\
\left(\mathrm{mg} \mathrm{kg}^{-1}\right.\end{array}$} & $\mathrm{K}^{+}$ & $\mathrm{Na}^{+}$ & $\mathrm{Ca}^{2+}$ & $\mathrm{Mg}^{2+}$ & $\mathrm{Al}^{3+}$ & $\mathrm{H}^{+}$ & \multirow{2}{*}{$\begin{array}{l}\text { CEes } \\
\mathrm{dS} \mathrm{m}^{-1}\end{array}$} \\
\hline & & & \multicolumn{6}{|c|}{ 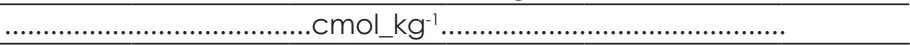 } & \\
\hline 6,24 & 10,79 & 48,00 & 0,28 & 1,82 & 7,41 & 5,23 & 0,00 & 3,07 & 2,50 \\
\hline \multicolumn{10}{|c|}{ Características físicas } \\
\hline \multicolumn{3}{|c|}{ Fração granulométrica $\mathrm{g} \mathrm{kg}^{-1}$} & & \multicolumn{2}{|c|}{ Umidade $\mathrm{kPa}$} & $A D$ & Porosidade & & \\
\hline Areia & Silte & Argila & textural & $\begin{array}{c}33,42 \\
\ldots \ldots \ldots \ldots \ldots\end{array}$ & $\begin{array}{c}1519,5 \\
\text { dag } \mathrm{kg}^{-1}\end{array}$ & AD & $\begin{array}{l}\text { total } \\
\mathrm{m}^{3} \mathrm{~m}^{-3}\end{array}$ & $\mathrm{~kg} \mathrm{dm}^{-3}$ & $\mathrm{~kg} \mathrm{dm}^{-3}$ \\
\hline 656,6 & 175,0 & 168,4 & FA & 28,84 & 10,42 & 18,42 & 53,64 & 1,27 & 2,74 \\
\hline
\end{tabular}

Após o preenchimento dos vasos, o teor de umidade do solo foi elevado próximo a capacidade de campo e, durante a condução da pesquisa o solo foi mantido próximo a capacidade de campo com irrigações diárias aplicando-se, em cada vaso, as águas correspondentes aos tratamentos, sendo o volume aplicado estimado pelo balanço de água: volume de água aplicado menos o volume de água drenado na irrigação anterior, acrescido de fração de lixiviação de 0,15, visando evitar o acúmulo excessivo de sais no solo (Ayers \& Westcot, 1999).

$A$ adubação com nitrogênio $(N)$, fósforo (P) e potássio (K) foi realizada baseando-se em recomendações contidas em Novais et al. (1991), sendo aplicado em cobertura junto com a água de irrigação, 100, 150 e $300 \mathrm{mg} \mathrm{kg}^{-1}$ de solo de $\mathrm{N}, \mathrm{K}_{2} \mathrm{O}$ e $\mathrm{P}_{2} \mathrm{O}_{5}$, respectivamente, em três aplicações iguais, em intervalos de quinze dias, com a primeira aplicação realizada aos 10 dias após o transplantio (DAT). Utilizaram-se como fonte de nitrogênio, fósforo e potássio, a ureia, o monoamônio fosfato e o cloreto de potássio, respectivamente. Visando suprir prováveis deficiências de micronutriente na cultura do pimentão, foram aplicados aos 30 DAT, uma solução contendo 1,5 $\mathrm{g} \mathrm{L}^{-1}$ de Ubyfol ( $\mathrm{N}-15 \%$; $\mathrm{P}_{2} \mathrm{O}_{5}-15 \% ; \mathrm{K}_{2} \mathrm{O}-15 \%$; $\mathrm{Ca}-1 \% ; \mathrm{Mg}-1,4 \% ; \mathrm{S}-2,7 \% ; \mathrm{Zn}$ $-0,5 \%$; B - $0,05 \%$; Fe - 0,5\%; Mn - 0,05\%; Cu - 0,5\%; 
Mo- $0,02 \%$ ) via foliar.

Fez-se a aplicação foliar de prolina semanalmente, a partir de 15 DAT, utilizando-se um borrifador, de modo a se obter o molhamento completo das plantas, em volume que variou de 10 a $40 \mathrm{~mL}$ por planta, conforme o estádio de desenvolvimento da planta.

Os efeitos dos tratamentos sobre a cultura do pimentão 'All Big' foram avaliados aos 90 DAT, através da determinação da altura de planta (AP), diâmetro de caule (DC), fitomassa seca de folha (FSF) e de caule (FSC). Já a produção foi mensurada, pelo o número de frutos por planta (NFr), a massa fresca (MFF)e o peso médio de frutos (PMF). Resssalta-se que a colheita dos frutos de pimentão foi realizada de uma única vez, aos 100 DAT.

A altura das plantas de pimentão foi obtida tomando-se como referência a distância do colo da planta até a inserção do meristema apical. $\bigcirc$ diâmetro de caule foi medido a $5 \mathrm{~cm}$ do colo da planta, com auxílio de um paquímetro digital. Para obtenção da fitomassa seca, a haste de cada planta foi cortada rente ao solo e, em seguida, foram separadas as distintas partes (caule e folha), e em seguida acondiconadas em saco de papel; posteriormente, foram postas para secar em estufa com ventilação forçada de ar, na temperatura de $65^{\circ} \mathrm{C}$, até a obtenção de peso constante. Posteriormente, o material foi pesado, obtendo-se a fitomassa das folhas e caule.

A contagem do númerode frutos por planta foi realizada de forma manual, onde consideraram apenas os que apresentaram mais de $80 \%$ da área dos frutos com a cor característica da cultivar (verde/vermelho). Após a contagem, os frutos foram lavados em água destilada e determinaram-se a massa fresca dos frutos em balança com precisão de $0,01 \mathrm{~g}$. O PMF foi obtido através da relação entre a MFF e o NFr.

Os dados coletados foram submetidos à análise de variância pelo teste $F$, quando significativo, realizou análise de regressão para o fator níveis de prolina e o teste de comparação de médias (Tukey a 0,05 de probabilidade) para os níveis de salinidade da água de irrigação, utilizando-se do software estatístico SISVAR-ESAL (Ferreira et al., 2011).

\section{Resultados e Discussão}

Constata-se por intermédio do resumo do teste " $F$ " (Tabela 2) haver efeito significativo dos níveis salinos (NS) sobre a altura de planta, o diâmetro de caule e a fitomassa seca de folhas e caule das plantas de pimentão 'All Big'. Com relação as doses de prolina (DP), verifica-se efeito significativo para todas as variáveis analisadas. A interação entre os fatores (NSXDP) para número de frutos, massa fresca de fruto e peso médio de frutos também foi significativa. Lacerda et al. (2012) estudando ao efeito da aplicação exógena de prolina (0, 5, 10 e $\left.20 \mathrm{mmol} \mathrm{L}^{-1}\right)$ no meloeiro irrigado com água salina (CEa: 0,3 e 5,0 dS $\mathrm{m}^{-1}$ ), observaram efeito significativo sobre a massa de frutos, fitomassa seca de folha e caule.

Tabela 2. Resumo do teste "F" referente a altura de planta (AP), o diâmetro de caule (DC), a fitomassa seca de folha (FSF), de caule (FSC), número de frutos (NFr), massa fresca de fruto (MFF)e peso médio de frutos (PMF) das plantas de pimentão 'All Big' irrigado com águas salinas sob diferentes doses de prolina

\begin{tabular}{lccccccc}
\hline \multirow{2}{*}{ Fonte de Variação } & \multicolumn{7}{c}{ Teste "F" } \\
\cline { 2 - 8 } & AP & DC & FSF & FSC & NFr & MFF & PMF \\
\hline Níveis salinos (NS) & $* *$ & $*$ & $*$ & $* *$ & $\mathrm{~ns}$ & $\mathrm{~ns}$ & $\mathrm{~ns}$ \\
Doses de prolina (DP) & $*$ & $*$ & $*$ & $* *$ & $*$ & $* *$ & $* *$ \\
$\quad$ Regressão Linear & $*$ & $* *$ & $*$ & $* *$ & $\mathrm{~ns}$ & $* *$ & $* *$ \\
Regressão Quadrática & $\mathrm{ns}$ & $\mathrm{ns}$ & $*$ & $*$ & $\mathrm{~ns}$ & $*$ & $*$ \\
Interação (NS*DP) & $\mathrm{ns}$ & $\mathrm{ns}$ & $\mathrm{ns}$ & $\mathrm{ns}$ & $*$ & $*$ & $*$ \\
Bloco & $\mathrm{ns}$ & $\mathrm{ns}$ & $\mathrm{ns}$ & $\mathrm{ns}$ & $\mathrm{ns}$ & $\mathrm{ns}$ & $\mathrm{ns}$ \\
$\mathrm{CV}(\%)$ & 12,08 & 9,62 & 17,10 & 18,63 & 19,33 & 20,32 & 19,36 \\
\hline ns, ${ }^{* *}, *$ respectivamente não significativo, significativo a p<0,01 e $\mathrm{p}<0,05$ & & & & & &
\end{tabular}


Por meio do teste de comparação de médias para altura de plantas (Figura 2A), constata-se que as plantas que foram submetidas a salinidade da água de irrigação de $0,6 \mathrm{dS} \mathrm{m}^{-1}$, a AP foi significativamente maior as que estavam submetidas a $3,0 \mathrm{dS} \mathrm{m}^{-1}$. Conforme se observa na Figura 2A, a CEa de $3,0 \mathrm{dS} \mathrm{m}^{-1}$ proporcionou uma diminuição de $14,08 \mathrm{~cm}(18,01 \%)$ no crescimento em altura em relação as plantas que foram irrigadas com $0,6 \mathrm{dS}^{-1}$. Diminuição na altura de plantas de pimentão, também foi observado por Nascimento et al. (2011), avaliando os efeitos da irrigação com água salina na formação de mudas de pimentão, cv. 'All Big', constatando declínio na AP de $70,5 \%$, aos 45 dias após trasplantio, nas plantas irrigadas com água de maior salinidade $\left(4,5 \mathrm{dS} \mathrm{m}^{-1}\right)$, em relação às que

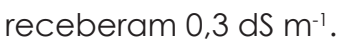
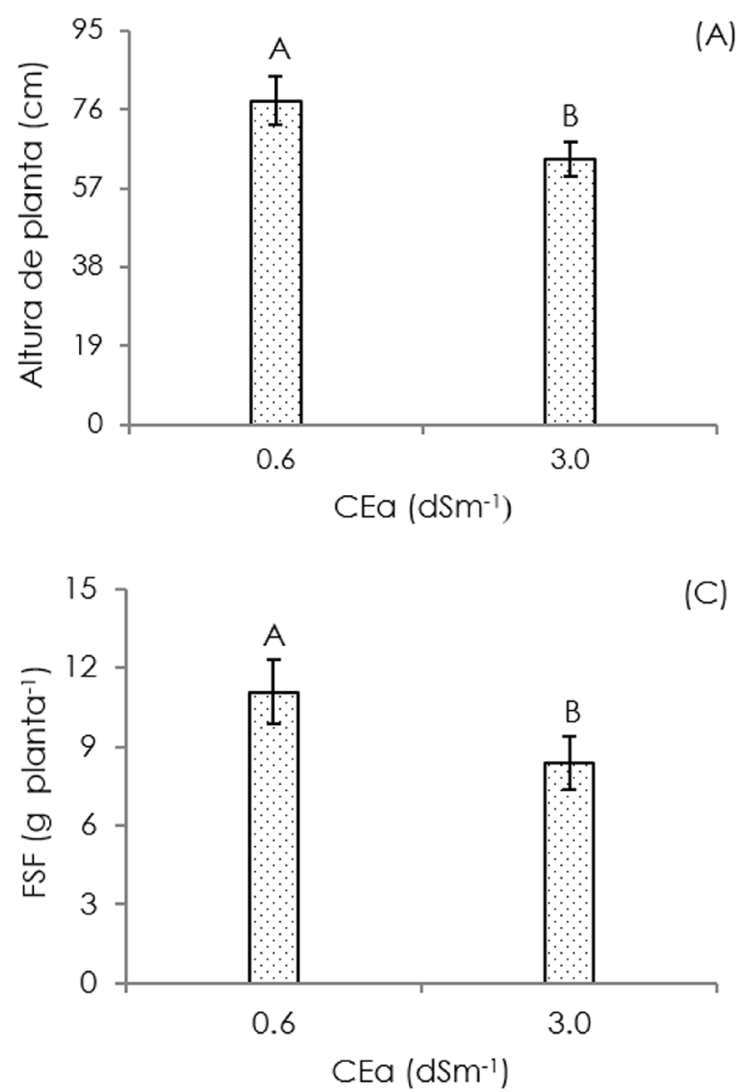

Acompanhando a mesma tendência observada para AP, a intensidade dos efeitos dos níveis salinos da água sobre o diâmetro de caule variou significativamente e por meio do teste de comparação de médias (Figura $2 \mathrm{~B}$ ), observa-se que a utilização de água com condutividade elétrica de $0,6 \mathrm{dS} \mathrm{m}^{-1}$, proporcionou maior crescimento em diâmetro caulinar (média de $10,73 \mathrm{~mm}$ ). Ao comparar às plantas submetidas à irrigação com água de maior nível salino (3,0 dS $\mathrm{m}^{-1}$ ), nota-se pelos dados (Figura $2 \mathrm{~B}$ ) que houve uma diminuição média do diâmetro caulinar de $1,00 \mathrm{~mm}(9,31 \%)$, em relação às plantas que estavam sob irrigação com $0,6 \mathrm{dS} \mathrm{m}^{-1}$. Vieira et al. (2016) estudando outra solanacea, o tomateiro, também observaram diminuição no DC sob condições de estresse salino (CEa variando de 0,3 e $\left.4,5 \mathrm{dSm}^{-1}\right)$, sendo a redução de $4,98 \%$ por incremento unitario da CEa.
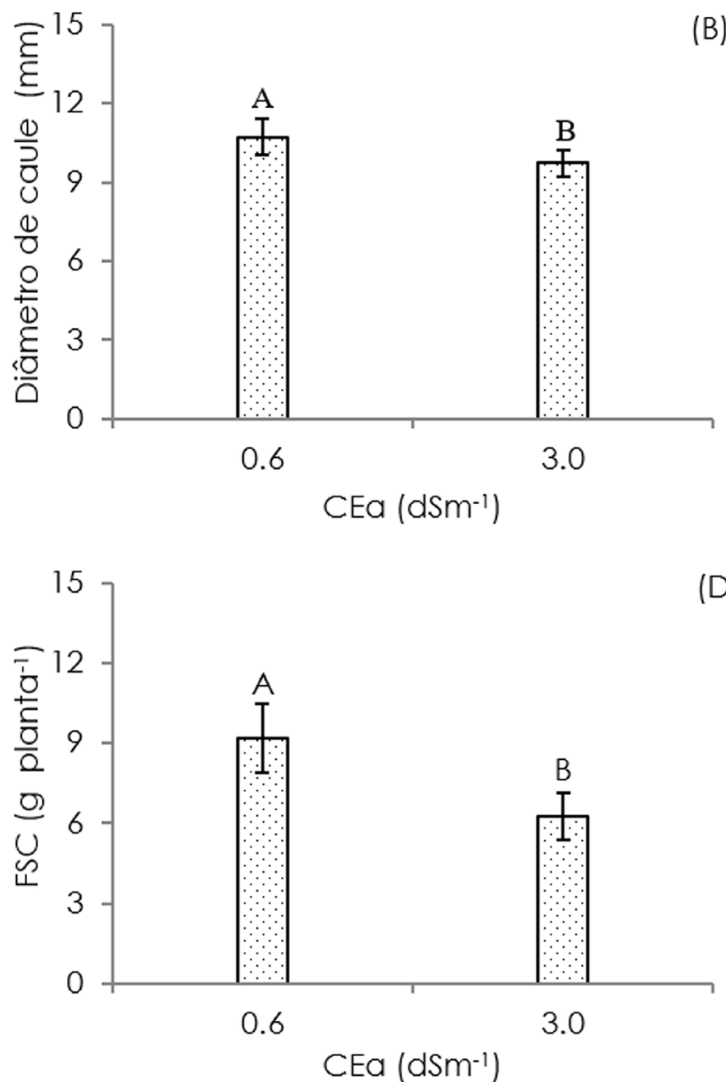

Figura 2. Altura de planta (A), diâmetro de caule (B), fitomassa seca de folhas (C) e de caule (D) do pimentão 'All Big'em função da salinidade da água de irrigação sob aplicação de prolina, aos 90 DAT. Barras representam o erro padrão da média $(n=4)$. Médias com letras diferentes significa que os tratamentos diferem entre si pelo teste de Tukey, p<0,05.

Percebe-se, por intermédio do teste de comparação de médias para fitomassa seca de folhas - FSF (Figura 2C) que as plantas sob irrigação com água de $0,6 \mathrm{dS} \mathrm{m}^{-1}$, tiveram maior acúmulo de FSF (11,09 $\left.\mathrm{g}_{\text {planta }}{ }^{-1}\right)$ quando comparadas com as plantas irrigadas com 3,0 dS $\mathrm{m}^{-1}$. Comparativamente observa-se, pelos dados expostos na Figura $2 \mathrm{C}$, que as plantas em 
que se aplicou água de baixa salinidade 10,6 $\mathrm{dS} \mathrm{m}^{-1}$ ), apresentaram um incremento na FSF de $2,72 \mathrm{~g}_{\text {planta }^{-1}}$, em relação à média obtida nas

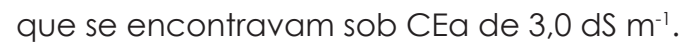

Para a fitomassa seca de caule (FSC), observa-se, através do teste de comparação de médias (Figura 2D) que as plantas submetidas à irrigação com água de $0,6 \mathrm{dS} \mathrm{m}^{-1} \mathrm{se}$ diferenciaram estatisticamente das que estavam sob CEa de 3,0 dS $\mathrm{m}^{-1}$. Ao analisar as médias obtidas nos diferentes tratamentos (Figura 2D), nota-se que as plantas sob irrigação com água

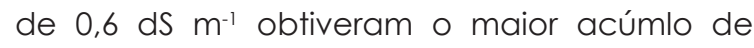
FSC $\left(9,21 \mathrm{~g} \mathrm{planta}^{-1}\right)$, sendo superior em $2,94 \mathrm{~g}$ planta $^{-1}$, as plantas irrigadas com o maior nível de salinidade $\left(3,0 \mathrm{dS}^{-1}\right)$. Freire et al. (2010), em experimento avaliando o efeito da salinidade no crescimento, na nutrição mineral e na produção de duas cultivares de tomateiro rasteiro (Santa Adélia e Meia Estaca) também verificaram, que o incremento do nível salino na água promoveu redução expressiva (17\%) na fitomassa seca da parte aérea.

De acordo com os resultados obtidos para as variáveis de crescimento (AP, DC, FSF e FSC), observou-se que os efeitos ocasionados pelo estresse salino sobre o pimentão 'All Big', obedeceram aos 90 DAT, a seguinte sequência: FSC $>F S F>A P>D C$. Desta forma, destaca-se a FSC, como a variável mais sensível ao estresse salino. Assim, a redução do crescimento do pimentão, em condições de elevada salinidade 13,0 dS $\mathrm{m}^{-1}$ ), deve estar relacionada com a ação do componente osmótico, além da possibilidade de ocorrência de toxicidade iônica, que dificulta a entrada de água nas células da planta (Santos et al., 2012), promove alterações na capacidade fotossintética (taxas de assimilação de $\mathrm{CO}_{{ }^{2}}$, transpiração foliar e condutância estomática) (Graciano et al., 2011), e inibe o crescimento das plantas.

Em relação aos efeitos das doses de prolina sobre a altura de planta (Figura $3 \mathrm{~A}$ ) e diâmetro de caule (Figura $3 B$ ) do pimentão, nota-se a partir das equações de regressão, efeito linear e decrescente, com diminuição de 4,77 e 5,72\% por aumento de $10 \mathrm{mmol} \mathrm{L}^{-1} \mathrm{na}$ concentração de prolina, equivalente a uma redução de $14,32 \%(9,81 \mathrm{~cm})$ e $17,17 \%(2,04$ $\mathrm{mm})$, respectivamente, na AP e DC das plantas submetidas a $30 \mathrm{mmol}^{-1}$, quando comparado com as que estavam sob o menor nível de prolina ( $\left.0 \mathrm{mmol}^{-1}\right)$ isto é sem aplicação.

A fitomassa seca de folhas também foi afetada de forma negativa pelo aumento na concentração de prolina e, segundo a equação de regressão (Figura $3 C$ ) $\circ$ modelo $\circ$ qual os dados obtiveram o melhor ajusto foi o quadrático, com o valor máximo para FSF $12,07 \mathrm{~g}$

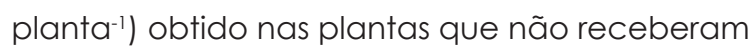
aplicação de prolina $\left(0 \mathrm{mmol}^{-1}\right)$, resultando em diminuição de 4,02 $\mathrm{g}_{\text {planta }}{ }^{-1}$, na fitomassa seca de folhas das plantas submetidas a 30 $\mathrm{mmol} \mathrm{L}^{-1} \mathrm{em}$ relação as que receberam $0 \mathrm{mmol}$ $\mathrm{L}^{-1}$ de prolina via foliar. Resultado divergente ao encontrado no presente estudo, foi encontrado por Lacerda et al. (2012) ao constatarem que o maior acúmulo de fitomassa seca de folhas do meloeiro foi encontrado ao aplicar dose de $11,46 \mathrm{mmol} \mathrm{L}^{-1}$ de prolina.

Através da equação de regressão referente a fitomassa seca de caule (Figura 3D), verifica-se ter sido quadrático o efeito das doses de prolina, onde se observa que à medida que se elevaram as doses de prolina de 0 para 30 mmol L-1, houve uma tendência de diminuição no acúmulo de FSC, sendo encontrado o valor máximo de 10,74 $\mathrm{g}_{\text {planta }}{ }^{-1} \mathrm{em}$ tratamento de $0 \mathrm{mmol} \mathrm{L}^{-1}$, e 0 mínimo de $6,69 \mathrm{~g}^{\text {planta }^{-1} \text { nas }}$ que estavam sob $30 \mathrm{mmol} \mathrm{L}^{-1}$ de prolina. Ao analisar os valores obtidos entre 0 e $30 \mathrm{mmol} \mathrm{L}^{-1}$, constata-se uma diminuição de 4,05 $\mathrm{g}_{\text {planta }}{ }^{-1}$ de pimentão 'All Big'. Lacerda et al. (2012), trabalhando com meloeiro tipo amarelo (Grupo Inodorus), também observaram maior redução na FSC nas plantas que receberam a maior dose de prolina $\left(20 \mathrm{mmol} \mathrm{L}^{-1}\right)$.

Pode-se inferir a partir dos resultados obtidos para AP, DC, FSF e FSC, que a aplicação de doses elevadas de prolina via foliar, possivelmente provocaram alterações no $\mathrm{pH}$ citosólico e no estado redox, causando danos irreversíveis às membranas celulares das plantas, afetando severamente 0 crescimento do pimentão 'All Big'. Tal fato pode ter ocorrido em função da concentração elevada de prolina fornecida (30 $\mathrm{mmol}^{-1}$ ), além do relativamente curto intervalo (uma semana) entre as aplicações. 

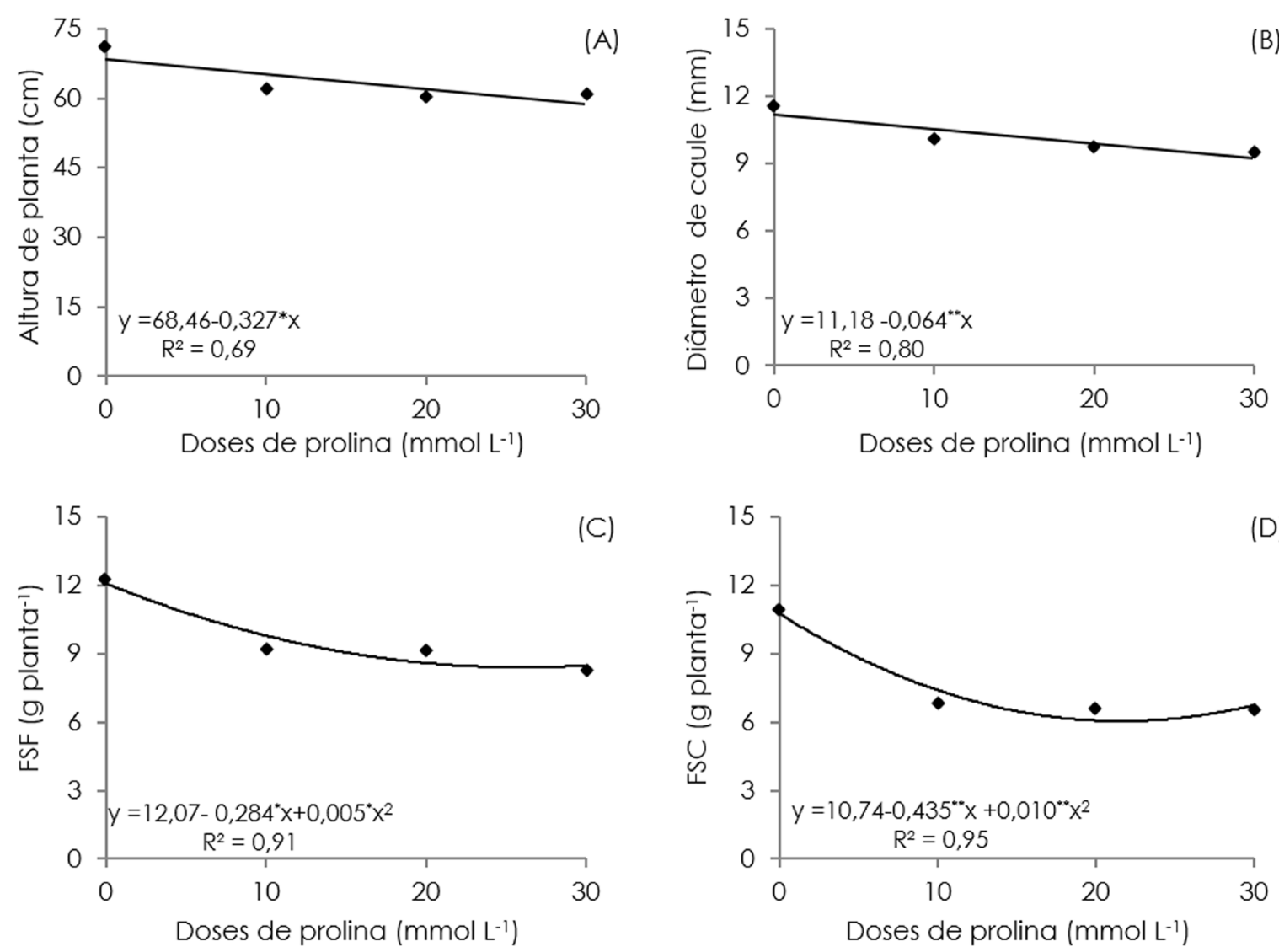

Figura 3. Altura de planta (A), diâmetro de caule (B), fitomassa seca de folhas (C) e de caule (D) do pimentão 'All Big'em função das doses de prolina, sob irrigação com águas salinas, aos 90 DAT.

Procedendo-se o desdobramento estatístico do efeito do fator salinidade da água de irrigação em relação as doses de prolina (Figura 4A), verifica-se nas plantas irrigadas com água de baixa salinidade $\left(0,6 \mathrm{dS} \mathrm{m}^{-1}\right)$ efeito quadrático, registrando-se maior número de frutos $(5,59)$ na dose de prolina de $17 \mathrm{mmol} \mathrm{L}^{-1}$. Baseado-se nesta dose, observa-se redução do número de frutos, da ordem de $26,65 \%$, quando comparado com a maior dose de prolina 130 $\left.\mathrm{mmol} \mathrm{L}^{-1}\right)$. Ainda para número de frutos de pimentão, o aumento da salinidade da água para $\left(3,0 \mathrm{dS} \mathrm{m}^{-1}\right)$ reduziu linearmente o número de frutos, quando associada a incrementos das doses de prolina, com decréscimos de 1,71 frutos $(34,72 \%)$ quando submetidas a aplicação de 30 mmol L-1 via foliar em relação a sem aplicação de prolina (Figura 4A).

A irrigação com água de distintas salinidades $\left(0,6\right.$ e 3,0 dS $\left.\mathrm{m}^{-1}\right)$ sob aplicação de prolina, promoveram efeito quadrático sobre o acúmulo de massa fresca de fruto do pimentão 'All Big', onde, segundo equações de regressão, os maiores valores $(241,5$ e 246,4
9 planta $^{-1}$ ) foram encontrados nas plantas submetidas a aplicações de 12 e $0 \mathrm{mmol} \mathrm{L}^{-1}$ de prolina nas respectivas salinidades (Figura 4B). Semelhante ao número de frutos (Figura 4A), percebe-se que o aumento das doses de prolina causaram reduções de 43,82 e 60,47\%, quando comparadas às plantas sem aplicação de prolina ao longo do ciclo, nas salinidade de 0,6 e 3,0 dS $\mathrm{m}^{-1}$, respectivamente.

Conforme dados contidos na Figura 4C, verifica-se, uma relação inversa entre as doses de prolina e o peso médio de frutos (PMF), ou seja quanto maior a dose de prolina aplicada via foliar, menor o PMF, independente do nível salino. Quando as plantas foram submetidas a maior dose de prolina (30 $\left.\mathrm{mmol} \mathrm{L}^{-1}\right)$ tiveram, comparando-se as plantas sem aplicação de prolina (0 mmol L-1), reduções de 42,72 e 52,89\%, sendo diminuída 25,89 e 32,37 g por fruto, quando irrigadas com águas de 0,6 e 3,0 dS m-1, respectivamente. Os resultados obtidos para NFr, MFF e PMF revelam que aplicação de prolina foi mais prejudicial quando plantas foram irrigadas com água de alta salinidade. 

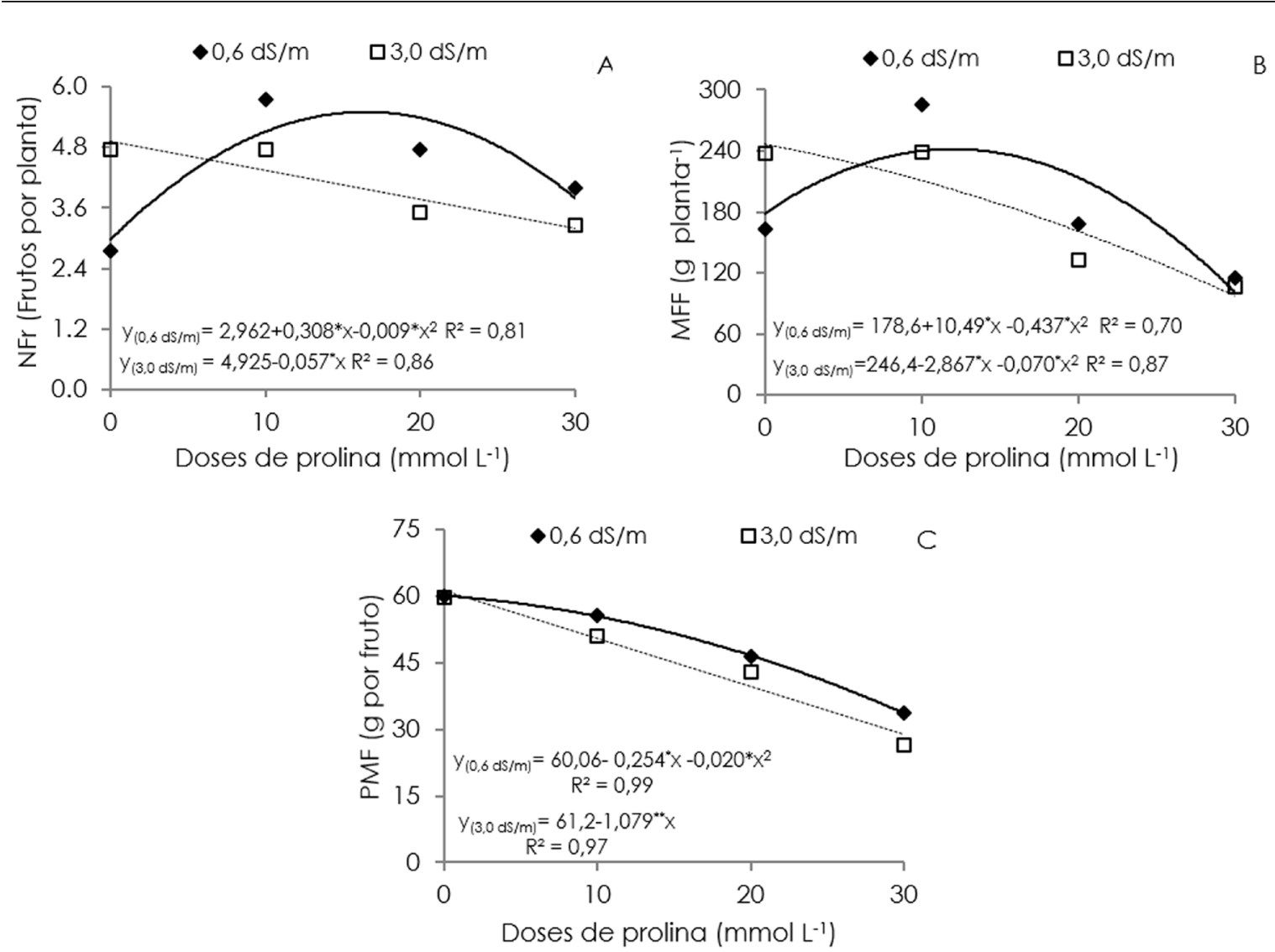

Figura 4. Número de frutos por planta - NFr (A), massa fresca de fruto - MFF (B) e peso médio de frutos - PMF (C) do pimentão 'All Big' irrigado com águas salinas e sob doses de prolina, aos 100 DAT.

Lacerda et al. (2012) avaliando-se efeito da aplicação exógena de prolina na redução do estresse no meloeiro irrigado com água salina, verificaram que o fornecimento de prolina reduziu os efeitos deletérios ocasionados pela salinidade até a dose de $12,56 \mathrm{mmol} \mathrm{L}^{-1}$, proporcionando um incremento na produção de frutos. Este fato é um indicativo de que a acumulação excessiva de prolina fornecido via foliar (Figura 4), possivelmente ocasionou potenciais osmóticos que juntamente com as concentrações salinas, foram severos a ponto de anular os possíveis efeitos atenuadores da prolina (Monteiro et al., 2014).

Deste modo, os efeitos mitigadores da aplicação de prolina difere entre os cultivos/ culturas adaptadas a certas condições ambientais, assim como em espécies tolerantes à seca ou à salinidade, e que o acúmulo deste soluto depende da duração do estresse e da concentração dos sais (Hever, 1994). Câmara et al. (2000), avaliando os efeitos de diferentes concentrações de $\mathrm{NaCl}(0,68,137$ e $205 \mathrm{mM})$ sobre o cultivo in vitro de calos de dois genótipos de milho (W64Ao2 e Arizona 8601), em meio de cultura, concluíram que a adição de prolina exógena na concentração de $6 \mathrm{mM}$ favoreceu o crescimento dos calos na ausência de $\mathrm{NaCl}$ e minorou os efeitos deletérios do estresse salino em ambos os genótipos no nível de sal mais elevado (250 mM de $\mathrm{NaCl}$ ). Na cultura do meloeiro, Lacerda et al. (2012) concluiram que o fornecimento de prolina na dose de $10,0 \mathrm{mmol}$ $\mathrm{L}^{-1}$ foi eficiente em reduzir o efeito estressante causado pela salinidade da água de irrigação.

\section{Conclusões}

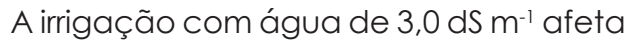
negativamente o crescimento do pimentão 'All Big', sendo a fitomassa seca de caule a variável mais sensível;

Os maiores valores para massa fresca, número e peso médio de frutos de pimentão são

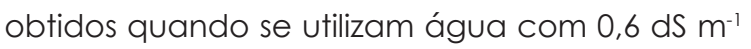
e doses de prolina de 12,0, 17,0 e 0 mmol L-1, respectivamente.

Doses crescentes de prolina não mitigam o efeito deletério provocado pela salinidade 
da água de irrigação de $3,0 \mathrm{dS} \mathrm{m}^{-1}$ sobre $\mathrm{O}$ crescimento e a produção do pimentão 'All Big'.

\section{Agradecimentos}

Ao Instituto Nacional de Ciência e Tecnologia em Salinidade - INCTSal, pelo financiamento do projeto, à Coordenação de Aperfeiçoamento de Pessoal de Nível Superior CAPES, pela concessão de bolsa de estudo ao primeiro autor e ao Professor Claudivan Feitosa de Lacerda - DENA/UFC, pelas contribuições visando a melhoria deste trabalho.

\section{Referências}

Araújo, J.S., Andrade, A.P. de, Ramalho, C.I., Azevedo, C.A.V.de.2009. Características de frutos de pimentão cultivado em ambiente protegido sob doses de nitrogênio via fertirrigação. Revista Brasileira de Engenharia Agrícola e Ambiental 13:152-157.

Ashraf, M., Akram, N. A., Alqurainy, F.; Foolad, M. R. 2011. Drought tolerance: roles of organic osmolytes, growth regulators, and mineral nutrients. Advances in Agronomy 111:249-296.

Ashraf, M., Foolad, M. R. 2007. Roles of glycine betaine and proline in improving plant abiotic stress resistence. Environmental and Experimental Botany 59:206-216.

Ayers, R.S., Westcot, D.W. 1999. A qualidade da água na agricultura. UFPB, Campina Grande, Brasil. 184p. (Estudos da FAO Irrigação e Drenagem, 29)

Camara, T.R., Willadino, L., Torné, J.M., Manick, A., Santo, M.A. 2000. Efeito do estresse salino e da prolina exógena em calos de milho. Revista Brasileira de Fisiologia Vegetal 12:146-155.

Cavalcante, L.F.; Rebequi, A.M.; Sena, G.S.A. de; Nunes, J.C. 2011 . Irrigação com águas salinas e uso de biofertilizante bovino na formação de mudas de pinhão-manso. Irriga 16:288-300.

Claessen, M.E.C. (org.). 1997. Manual de métodos de análise de solo. 2. ed. rev. atual. Rio de Janeiro: Embrapa-CNPS. 212p. EmbrapaCNPS. Documentos, 1.

Echer, M.M., Fernandes, M.C.A., Ribeiro, R.L.D., Peracchi, A.L. 2002. Avaliação de genótipos de Capsicum para resistência a ácaro branco. Horticultura Brasileira 20:217-221.

Ferreira, D.F. 2011 . Sisvar: a computer statistical analysis system. Ciência e Agrotecnologia 35:1039-1042.

Freire, A.L. de O., Saraiva, V.P., Miranda, J.R.P. de,
Bruno, G.B. 2010. Crescimento, acúmulo de íons e produção de tomateiro irrigado com água salina. Semina: Ciências Agrárias 31:1133-1 144.

Graciano, E.S.A., Nogueira, R.J.M.C., Lima, D.R.M., Pacheco, C.M., Santos, R.C. 2011. Crescimento e capacidade fotossintética da cultivar de amendoim BR 1 sob condições de salinidade. Revista Brasileira de Engenharia Agrícola e Ambiental 15:794-800.

Greenway, H., Munns, R. 1980. Mechanisms of salt tolerance in nonhalophytes. Annual Review of Plant Physiology 31:149-190.

Hever, B. 1994. Osmoregulatory role of proline in water and salts stressed plants. In: Pessaraki, $M$. (Ed.) Handbook of plant and crop stress. Marcel Dekker, New York, USA. p.363-383.

Lacerda, F.H.D., Pereira, F.H.F., Neves, D. da S., Borges, F.Q. da C., Campos Júnior, J.E. 2012. Aplicação exógena de prolina na redução do estresse salino em meloeiro. Revista Verde de Agroecologia e Desenvolvimento Sustentável 7:218-227.

Monteiro, J.G., Cruz, F.J.R., Nardin, M.B., Santos, D.M.M. 2014. Crescimento e conteúdo de prolina em plântulas de guandu submetidas a estresse osmótico e à putrescina exógena. Pesquisa Agropecuária Brasileira 49:18-25.

Nascimento, J.A.M., Cavalcante, L.F., Santos, P.D. dos, Silva, S.A. da, Vieira, M. da S., Oliveira, A.P. de. 2011. Efeito da utilização de biofertilizante bovino na produção de mudas de pimentão irrigadas com água salina. Revista Brasileira de Ciências Agrárias 6:258-264.

Neves, A.L.R., Lacerda, C.F. de, Teixeira, A. dos S., Costa, C.A.G., Gheyi, H.R. 2010. Monitoring soil coverage and yield of cowpea furrow irrigated with saline water. Revista Ciência Agronômica 41:59-66.

Novais, R. F., Neves, J. C. L., Barros, N. F. 1991. Ensaio em ambiente controlado. In: Oliveira, A. J.; Garrido, W. E.; Araújo, J. D. de; Lourenço, S. (coord.). Métodos de pesquisa em fertilidade do solo. Embrapa SEA, Brasília, Brasil. p.189-253.

Resende, G.M., Alvarenga, M.A.R., Yuri, J.E., Souza, R.J. 2010. Doses de nitrogênio e molibdênio no rendimento e teor de micronutrientes em alface americana. Horticultura Brasileira 28: 266-270.

Santos, D.B. dos, Ferreira, P.A., Oliveira, F.G. de, Batista, R.O., Costa, A.C., Cano, M.A.O. 2012. Produção e parâmetros fisiológicos do amendoim em função do estresse salino. Idesia 30:69-74.

Silva, E.N., Silveira, J.A.G., Rodrigues, C.R.F., Lima, C.S., Viégas, R.A. 2009. Contribuição de 
solutos orgânicos e inorgânicos no ajustamento osmótico de pinhão-manso submetido à salinidade. Pesquisa Agropecuária Brasileira 44:437-445.

Silva, J.L. de A., Alves, S.S.V., Nascimento, I.B. do: Medeiros, J.F. de, Targino, A.J. de O., Linhares, P.S.F. 2014. Teores foliares no pimentão submetido à estrese salino em diferentes solos. Agropecuária Científica no Semiárido 10:77-82.

Sousa, G.G., Marinho, A.B., Albuqueruqe, A.H.P., Viana, T.V.A., Azevedo, B.M. 2012. Crescimento inicial do milho sob diferentes concentrações de biofertilizante bovino irrigado com águas salinas. Revista Ciência Agronômica 43:237-245.

Trovato, M., Mattioli, R., Costantino, P. 2008. Multiple roles of proline in plants stress tolerance and development. Rendiconti Lincei 19:325-346.

Verbruggen, N., Hermans, C. 2008. Proline accumulation in plants: a review. Amino Acids 35:753-759.

Vieira, I.G.S., Nobre, R.G., Dias, A.S., Pinheiro, F.W.A. 2016. Cultivo do tomateiro cereja irrigado com águas salinizadas e adubação nitrogenada. Revista Brasileira de Engenharia Agrícola e Ambiental 20:27-33. 